\title{
Biosorption of copper(II) onto spent biomass of Gelidiella acerosa (brown marine algae): optimization and kinetic studies
}

\author{
John Babu Dulla ${ }^{1} \cdot$ Mohan Rao Tamana ${ }^{2} \cdot$ Sumalatha Boddu ${ }^{3} \cdot$ King Pulipati $^{4} \cdot$ Krupanidhi Srirama $^{1}$
}

Received: 10 February 2019 / Accepted: 16 December 2019 / Published online: 13 January 2020

(c) The Author(s) 2020

\begin{abstract}
This study exclusively focused on the potential application of an inexpensive and sustainable waste macro-algal biomass as an adsorbent for biosorption of copper ions from aqueous medium. After extraction of agar from brown macro-marine algae Gelidiella acerosa, the residual biomass without any further treatment was used as an adsorbent for the expulsion of copper from wastewater. Physicochemical parameters of biosorption like initial $\mathrm{pH}$, initial concentration of $\mathrm{Cu}$ (II) solution and biosorbent dosage were optimized using response surface methodology. The maximum copper biosorption potential of $96.36 \%$ was observed at optimum conditions of $\mathrm{pH}$ of 5.31, initial concentration of $23.87 \mathrm{mg} / \mathrm{l}$ and biosorbent dosage of $0.41 \mathrm{~g} / \mathrm{l}$. Adopting FTIR and SEM techniques, the surface morphological features of biosorbent were studied. The pseudosecond-order kinetic model was found to be a proper approach to describe biosorption kinetics. All these results confirmed that spent $G$. acerosa could be considered as an efficient, eco-friendly and economic alternative for $\mathrm{Cu}$ (II) removal from aqueous solution.
\end{abstract}

Keywords Biosorption $\cdot$ Copper $\cdot$ Gelidiella acerosa $\cdot$ Kinetics $\cdot$ Optimization

\section{Introduction}

Enhanced industrial activities with technological innovations and anthropogenic activities with increased population had led to the excessive discharge of heavy metal contaminated wastewater into the aquatic systems. Industrial wastewater infused with heavy metal residues is known to be the most toxic to the aquatic environment and the health of living species (Anantha and Kota 2016). Moreover, heavy metals are non-degradable and accumulate in the environment through

John Babu Dulla

johnbabu_d@ rediffmail.com

1 Department of Biotechnology, Vignan's Foundation for Science Technology and Research, Vadlamudi, Guntur, Andhra Pradesh 522213, India

2 Department of Chemical Engineering, Bapatla Engineering College, Bapatla, Guntur, Andhra Pradesh 522101, India

3 Department of Chemical Engineering, Vignan's Foundation for Science Technology and Research, Vadlamudi, Guntur, Andhra Pradesh 522213, India

4 Department of Chemical Engineering, Andhra University College of Engineering, Visakhapatnam, Andhra Pradesh 530003, India the food chain. So, heavy metal-tainted wastewater should be treated before discharging into the aquatic environment.

Among the deleterious heavy metals, copper and its composites are the most common metal pollutants in the environment with the global annual discharge estimated at 939,000 metric tons (Abdolali et al. 2017; Wuana and Okieimen 2011). The most common sources of origin are wastewaters from refineries, metal plating facilities, tanneries, mining operators, etc. (Izquierdo et al. 2010; Calero et al. 2018; Kumar and Chawla 2014). A trace amount of copper is an essential micronutrient for cell functioning. However, excessive intake leads to malfunctioning of liver and brain, mucosal irritation, intestine ulcers, renal system failure and nervous system damage (Kumar and Chawla 2014; Ekere et al. 2016). Persistent copper exposure can also cause Wilson's disease (Thilagan et al. 2015; Krupanidhi et al. 2008). Hence, meticulous treatment of copper-contaminated water is indispensable before discarding into water systems in order to protect water sources and human health.

Several technologies for the treatment of copper-loaded wastewater have been employed by researchers across the globe. They included precipitation, cementation, membrane separation, oxidation, solvent extraction and ion exchange (Fu and Wang 2011; Dursun 2006). But the majority of 
these methods are unfit for the treatment when metal concentrations in effluents are less than $100 \mathrm{mg} / \mathrm{l}$ (Benaissa and Elouchdi 2007). Moreover, these processes create sludge disposal problems by generating metal-bearing sludge. Over recent years, the removal of copper from wastewater by adsorption attracted the attention of researchers. Studies have been focused on the use of waste or byproducts of various sources such as industries and agriculture as adsorbents, whose use can also eliminate the sludge disposal problem.

Various biological materials have been tested for effective metal recovery from wastewaters which include plant residual biochar, microorganism, activated sludge and micro- and macro-algae (Anastopoulos and Kyzas 2015; Awual 2015; Guang et al. 2012). Among these biomaterials, algae have been reported as most suitable biosorbents due to their abundant availability, high metal-binding affinity, reusability and good surface characteristics (Sari and Tuzen 2008; Babu et al. 2018). Algae's functionality is mainly attributed to their surface functional groups such as carboxylic, amino and hydroxyl, which binds with metal ions through different interactions like electrostatic forces, ion exchange or complexation (Kiran and Thanasekaran 2011).

Most of the studies were focused on using pure and surface-modified algae as biosorbents for recovery of heavy metals; use of algal waste biomass as biosorbents after extracting valuable products from it was not attempted. In this work, algal biomass after extraction of agar from Gelidiella acerosa (G. acerosa) which is known to be a major source for agar extraction in India was selected as a biosorbent for the expulsion of $\mathrm{Cu}(\mathrm{II})$ from aqueous solutions. The objective of the current investigation was to evaluate the feasibility of $\mathrm{Cu}(\mathrm{II})$ biosorption by spent $G$. acerosa and optimize the operational conditions for biosorption of $\mathrm{Cu}$ (II) from wastewater. The experimental data are analyzed using different kinetic and equilibrium isotherm models.

\section{Materials and methods}

\section{Preparation of spent G. acerosa}

Spent waste of marine macro-alga G. acerosa was selected as a biosorbent in the present study. Carmel G. acerosa plants were collected from Gulf of Mannar, Tamil Nadu, India. These algal strains were cleaned many times in tap and double distilled water to remove dirt, salts and external debris; then it was kept dried in open atmosphere for 3 days and further dried in an oven at controlled temperature of $70{ }^{\circ} \mathrm{C}$ for another 2 days. Dried G. acerosa, $6 \mathrm{~g}$, was transferred to $500 \mathrm{ml}$ of $1 \mathrm{M} \mathrm{NaOH}$ and heated the mixture at $80{ }^{\circ} \mathrm{C}$ for $4 \mathrm{~h}$. The algal biomass was separated from the $\mathrm{NaOH}$ solution and washed several times with tap water. To extract agar, the algal biomass was taken in $200 \mathrm{ml}$ distilled water and heated at $85^{\circ} \mathrm{C}$ for $2 \mathrm{~h}$. The mixture was homogenized in a blender and filtered using filter cloth. After filtration, the biomass was dried at $60^{\circ} \mathrm{C}$ for $24 \mathrm{~h}$ (Kumar and Fotedar 2009; Villanueva et al. 2010). The dried biomass of algae was chopped into small pieces and ground in domestic grinder. The granulated biomass was sieved through a standard set of sieves and packed in an airtight container.

\section{Reagents and chemicals}

A standard copper solution (1000 ppm) was prepared by dissolving $3.91 \mathrm{~g}$ of analytical grade $\mathrm{CuSO}_{4} 5 \mathrm{H}_{2} \mathrm{O}$ (Merck India Pvt. Ltd.) in $1000 \mathrm{ml}$ of double distilled water. Working standards of initial $\mathrm{Cu}$ (II) concentrations between 20 and $100 \mathrm{ppm}$ were prepared by progressive dilutions of standard copper solution. The initial $\mathrm{pH}$ of working standards was normalized using $0.1 \mathrm{M} \mathrm{HCl}$ and $0.1 \mathrm{M} \mathrm{NaOH}$

\section{Surface characterization}

FTIR spectra of fresh and $\mathrm{Cu}(\mathrm{II})$-treated spent $G$. acerosa were recorded by following $\mathrm{KBr}$ pellet method using Bruker UK (ATR) FTIR spectrophotometer in the spectrum range of $4000-400 \mathrm{~cm}^{-1}$ and presented in Fig. 1. SEM images of fresh and $\mathrm{Cu}(\mathrm{II})$-treated spent $G$. acerosa were taken using Hitachi S-3700 N SEM (at accelerating voltage $10 \mathrm{kV}$ ) and presented in Fig. 2.

\section{Design of experiments}

Response surface methodology (RSM) is a multivariable optimization tool used to find the optimal response of a process which is a function of several independent variables through

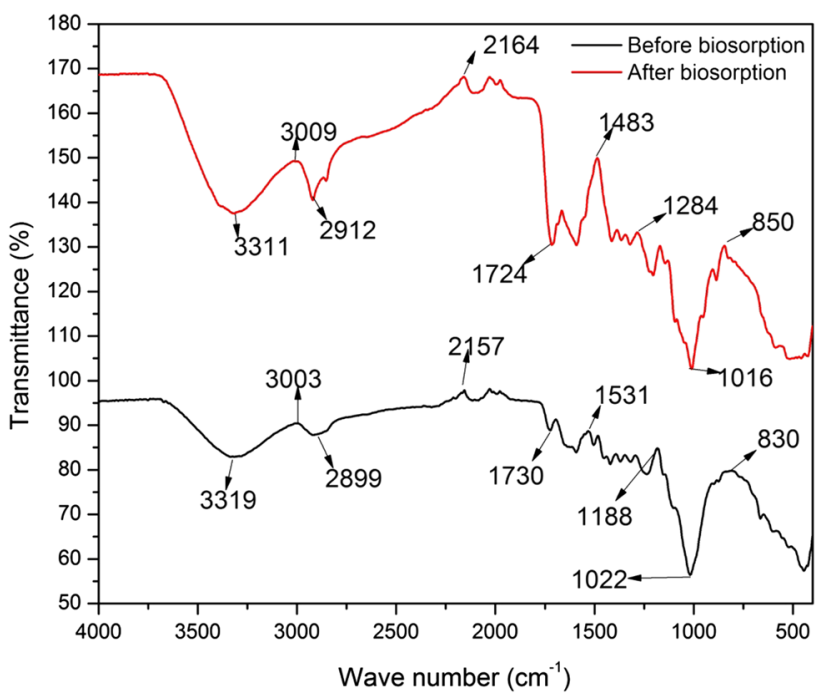

Fig. 1 FTIR spectrograph of spent G. acerosa (a) before biosorption and (b) after biosorption of $\mathrm{Cu}$ (II) 

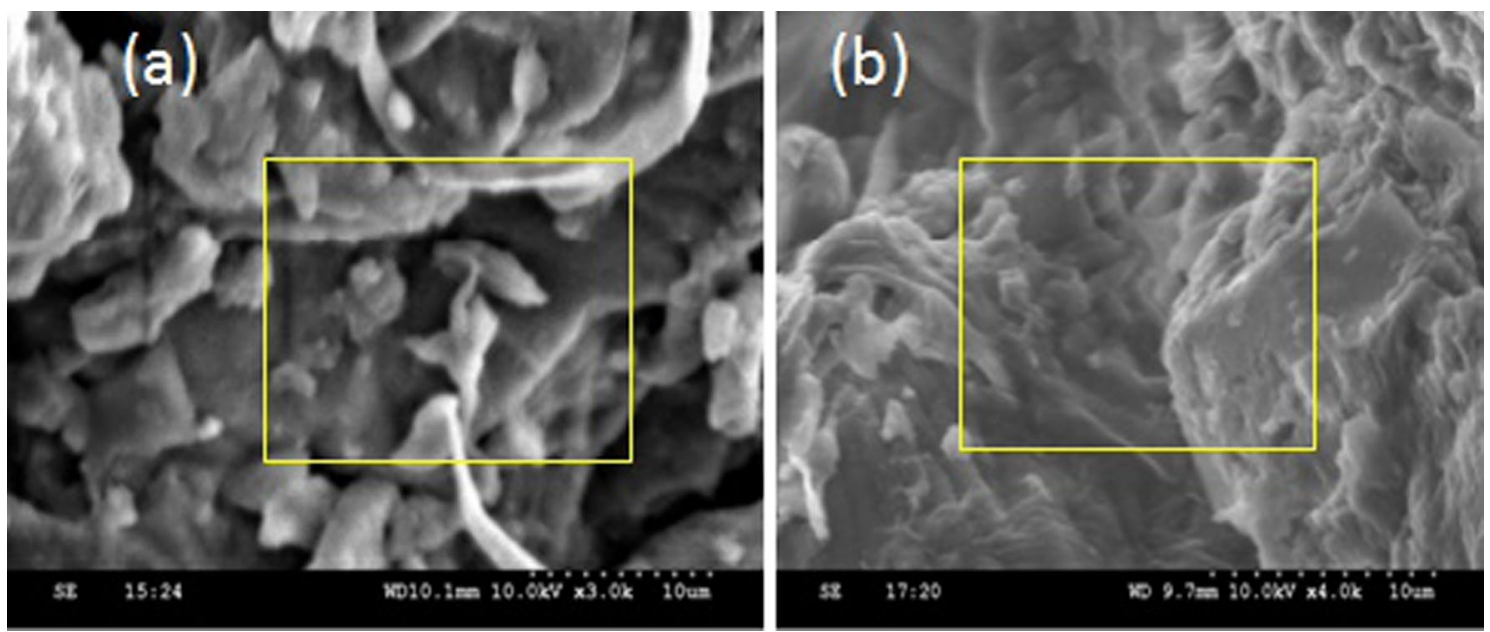

Fig. 2 SEM of spent G. acerosa, $\mathbf{a}$ before biosorption and $\mathbf{b}$ after biosorption of $\mathrm{Cu}(\mathrm{II})$

Table 1 Levels of different process variables used in FCCCD for biosorption of $\mathrm{Cu}(\mathrm{II})$ onto spent $G$. acerosa

\begin{tabular}{llll}
\hline Factors & \multicolumn{3}{l}{ Range and levels } \\
\cline { 2 - 4 } & -1 & 0 & 1 \\
\hline A: pH range & 2 & 4.5 & 7 \\
B: Initial Cu(II) concentration (mg/l) & 20 & 60 & 100 \\
C: Spent G. acerosa dosage (g/l) & 0.1 & 0.3 & 0.5 \\
\hline
\end{tabular}

fitting the experimental data to a second-order equation. The three major steps of RSM include design of experimental matrix, development of mathematical model and optimization of response of interest (Chatterjee et al. 2012; Sadhu et al. 2014). To assess the optimum biosorption of $\mathrm{Cu}$ (II) (Y) onto spent $G$. acerosa, three independent variables were followed: initial $\mathrm{pH}$ of $\mathrm{Cu}$ (II) solution (A), initial $\mathrm{Cu}$ (II) concentration in solution (B) and dosage of spent G. acerosa (C). Experiments were designed using face-centered central composite design (FCCCD) of RSM. The ranges and levels $(-1,0,+1)$ of independent variables are presented in Table 1 . The secondorder polynomial equation relating the independent process variables and the response of interest, i.e., percentage biosorption of $\mathrm{Cu}(\mathrm{II})$, is presented in the form of Eq. (1):

$Y=\beta_{0}+\sum_{i=1}^{n} \beta_{i} X_{i}+\sum_{i=1}^{n} \beta_{i i} X_{i}^{2}+\sum_{i=1}^{n-1} \sum_{j=i+1}^{n} \beta_{i j} X_{i} X_{j}$

where $Y$ is response of system, $\beta_{0}$ is constant, $\beta_{i}$ is linear constant, $\beta_{i i}$ is quadratic constant and $X_{i}$ is independent variable.

\section{Experimental procedure}

All the experiments designed using FCCCD were performed in batch process. The reaction mixtures of each $30 \mathrm{ml}$ as specified in design matrix were taken in $250-\mathrm{ml}$ conical flasks and stirred in orbital shaker at $180 \mathrm{rpm}$. All the experiments were conducted up to predetermined equilibrium contact time of $40 \mathrm{~min}$ (not discussed here) and holding at ambient temperature. Samples were collected and filtered using Whatman filter paper (No. 1). The metal concentrations of filtrate were measured using atomic absorption spectroscopy (AAS PerkinElmer AAnalyst 400). All experiments were repeated thrice, and statistically analyzed values have been reported. The $\mathrm{Cu}$ (II) uptake by spent G. acerosa (mg of copper per g spent G. acerosa) is calculated using Eq. (2):

$q_{\mathrm{e}}=\frac{V\left(C_{\mathrm{o}}-C_{\mathrm{t}}\right)}{1000 m}$

where $C_{\mathrm{o}}$ and $C_{\mathrm{t}}$ are the concentrations of $\mathrm{Cu}$ (II) ions (mg/l) before and after equilibrium contact time, $V$ is the volume of $\mathrm{Cu}(\mathrm{II})$ aqueous solution taken $(\mathrm{ml})$ and $m$ is the weight of spent $G$. acerosa (g) added to $\mathrm{Cu}(\mathrm{II})$ solution.

\section{Kinetic models}

Kinetic modeling of biosorption is very much essential to scale up the process for industrial-scale operations. Moreover, kinetics of a reaction describes the nature of the process, reaction pathways and exact interface resistance for mass transfer. Hence, in the present study fresh experiments were conducted for kinetics analysis with different initial $\mathrm{Cu}$ (II) concentrations ranging from 20 to $100 \mathrm{mg} / \mathrm{l}$ at optimum $\mathrm{pH}$ and temperature of $30^{\circ} \mathrm{C}$, and the data were fitted to various kinetic models such as pseudo-first-order, pseudo-secondorder, intra-particle diffusion (Weber and Morris 1964), Boyd (Boyd et al. 1947) and Elovich models (Kellner et al. 2004): 
$\log \left(q_{\mathrm{e}}-q_{\mathrm{t}}\right)=\log q_{\mathrm{e}}-k_{1}(t / 2.303)$

$\frac{t}{q_{\mathrm{t}}}=\left(\frac{1}{k_{2} q_{\mathrm{e}}^{2}}\right)+\left(\frac{t}{q_{\mathrm{e}}}\right)$

$q_{\mathrm{t}}=k_{\mathrm{id}} \mathrm{t}^{1 / 2}+C$

$\beta_{\mathrm{t}}=-0.4977-(1-F)$

$q_{\mathrm{t}}=\left(\frac{1}{b}\right) \ln (a b)+\frac{1}{b} \ln t$

where $k_{1}$ and $k_{2}$ are the first- and second-order rate constants, $q_{\mathrm{e}}(\mathrm{mg} / \mathrm{g})$ and $q_{\mathrm{t}}(\mathrm{mg} / \mathrm{g})$ are $\mathrm{Cu}(\mathrm{II})$ uptake at equilibrium and time $t(\mathrm{~min})$, respectively, $k_{\mathrm{id}}$ is diffusion constant, $C$ is the constant related to film thickness, $F$ is relative $\mathrm{Cu}(\mathrm{II})$ uptake, $\beta_{\mathrm{t}}$ is a mathematical equation, ' $a$ ' is initial rate of biosorption and ' $b$ ' is the constant related to activation energy for chemisorption.

\section{Results and discussion}

\section{Characterization of spent G. acerosa using FTIR and SEM}

Algal cell wall is composed of many functional groups like hydroxyl, carboxyl, amine, sulfate and phosphate, which play a major role in metal binding (Jerold and Sivasubramanian 2016). FTIR is a valuable tool to exploit chemical constituents present on the surface of a material, and it is used to disclose qualitative information regarding the organic compounds (Lammers et al. 2009; Kannan 2014). FTIR spectra of spent $G$. acerosa before and after biosorption of $\mathrm{Cu}(\mathrm{II})$ were recorded at frequencies from 4000 to $400 \mathrm{~cm}^{-1}$ and presented in Fig. 1. Several peaks (Fig. 1a) were observed on the surface of G. acerosa before biosorption, indicating the presence of various functional groups which are responsible for the binding of copper. The medium peak at $3319 \mathrm{~cm}^{-1}$ represents $\mathrm{N}-\mathrm{H}$ stretching vibration that showed the presence of amine group on the surface of biosorbent. The peaks at 3003 and $2899 \mathrm{~cm}^{-1}$ represent C-H bonds that indicate the presence of carboxylic groups (Jerold and Sivasubramanian 2016; Dulla et al. 2018). In most of the brown algae, $70 \%$ of cell wall functional groups are carboxylic and amino groups; these groups play a vital role in metal binding (Meseguer et al. 2016). The peaks at wave numbers of 1730 and $1531 \mathrm{~cm}^{-1}$ are indicative of the presence of $\mathrm{S}, \mathrm{C}=\mathrm{O}$, $\mathrm{NO}_{2}$ groups (Khan et al. 2016). Strong stretching vibrations in the range of $1250-970 \mathrm{~cm}^{-1}$ are indication of the presence of alcohols and phenols. The peak at $830 \mathrm{~cm}^{-1}$ is associated with the absorbance of $\mathrm{O}-\mathrm{H}$ group indicating the presence of carboxylic groups. Therefore, it is inferred that the surface of spent $G$. acerosa comprises functional groups like carboxylic acids, amino, alkenes and alkyl groups.

Comparison of FTIR spectra of spent G. acerosa loaded with copper (Fig. 1b) with that of unloaded revealed significant changes. Formation of new peaks at 1438 and $1248 \mathrm{~cm}^{-1}$ and disappearance of peak at $1724 \mathrm{~cm}^{-1}$ are the clear indications of a possible chemical reaction between copper ions and surface functional groups. Further shifting of peaks in the range of $3500-2800 \mathrm{~cm}^{-1}$ pertaining to carboxylate group reveals the involvement of $\mathrm{C}-\mathrm{H}$ group in the adsorption of copper ions onto the biosorbent. Moreover, shifting of peak at $830 \mathrm{~cm}^{-1}$ before biosorption to $850 \mathrm{~cm}^{-1}$ after biosorption also discloses the binding of copper ions to amine group present on the surface of spent $G$. acerosa.

The SEM analysis of spent $G$. acerosa was carried out to study the surface texture and its modification derived from sorbate interactions, and the result obtained is shown in Fig. 2. It is apparent from the SEM image shown in Fig. 2a that spent $G$. acerosa has a very rough surface with a good number of pores where there is a good possibility for biosorption of heavy metals ions. A decrease in the number of pores, the presence of shiny particles over the surface and apparent smooth surface after biosorption as shown in Fig. $2 b$ indicate the sorption of copper onto the surface of biosorbent.

\section{Response surface methodology (RSM)}

Face-centered central composite design (FCCCD) was used for the optimization of $\mathrm{Cu}$ (II) biosorption onto spent $G$. acerosa by taking input variables as shown in Table 1. A total of 20 experiments designed by FCCCD were conducted, and the obtained results were used for the analysis. Complete design matrix generated using FCCCD with coded variables, response reported from experiments and predicted response for biosorption of $\mathrm{Cu}$ (II) onto spent $G$. acerosa is given in Table 2.

\section{ANOVA for response surface quadratic model}

Significance of each individual process variables and overall model significance was studied using analysis of variance (ANOVA), and the results are presented in Table 3. The ANOVA results showed very small "model $P$ value" $(<0.0001)$ and large "lack of fit $P$ value" $(0.989)$, which discloses the statistical significance of the model. The results also showed that $R_{\text {adj }}^{2}$ value (0.989) is in good agreement with $R_{\text {pred }}^{2}$ value (0.999), indicating that there is well-linearized fitness between the experimental values and modelpredicted values. Overall, the ANOVA analysis suggests that the model can be used to navigate the design spaces on 
Table 2 Experimental design (FCCCD) in coded values of observed and predicted response for biosorption of $\mathrm{Cu}$ (II) onto spent G. acerosa

\begin{tabular}{|c|c|c|c|c|c|}
\hline \multirow[t]{2}{*}{ Standard order } & \multirow[t]{2}{*}{$\mathrm{pH}$} & \multirow{2}{*}{$\begin{array}{l}\text { Initial concentra- } \\
\text { tion }(\mathrm{mg} / \mathrm{l})\end{array}$} & \multirow{2}{*}{$\begin{array}{l}\text { Biosorbent } \\
\text { Dosage }(g)\end{array}$} & \multicolumn{2}{|l|}{ \% Removal } \\
\hline & & & & Experimental & RSM predicted \\
\hline 1 & -1 & -1 & -1 & 41.35 & 41.44 \\
\hline 2 & 1 & -1 & -1 & 86.55 & 86.65 \\
\hline 3 & -1 & 1 & -1 & 24.84 & 24.94 \\
\hline 4 & 1 & 1 & -1 & 73.36 & 73.45 \\
\hline 5 & -1 & -1 & 1 & 45.84 & 45.93 \\
\hline 6 & 1 & -1 & 1 & 90.20 & 90.30 \\
\hline 7 & -1 & 1 & 1 & 28.49 & 28.59 \\
\hline 8 & 1 & 1 & 1 & 76.18 & 76.27 \\
\hline 9 & -1 & 0 & 0 & 38.27 & 37.91 \\
\hline 10 & 1 & 0 & 0 & 84.72 & 84.36 \\
\hline 11 & 0 & -1 & 0 & 92.01 & 91.65 \\
\hline 12 & 0 & 1 & 0 & 76.75 & 76.39 \\
\hline 13 & 0 & 0 & -1 & 81.49 & 81.12 \\
\hline 14 & 0 & 0 & 1 & 85.14 & 84.77 \\
\hline 15 & 0 & 0 & 0 & 84.75 & 84.83 \\
\hline 16 & 0 & 0 & 0 & 83.55 & 84.83 \\
\hline 17 & 0 & 0 & 0 & 85.16 & 84.83 \\
\hline 18 & 0 & 0 & 0 & 84.28 & 84.83 \\
\hline 19 & 0 & 0 & 0 & 84.69 & 84.83 \\
\hline 20 & 0 & 0 & 0 & 85.11 & 84.83 \\
\hline
\end{tabular}

Table 3 ANOVA for quadratic surface model for biosorption of $\mathrm{Cu}(\mathrm{II})$ onto spent G. acerosa

\begin{tabular}{lrrrrr}
\hline Source & Sum of squares & $d f$ & Mean square & $F$ value & $P$ value prob. $>F$ \\
\hline Model & 9235.62 & 9 & 1026.18 & 3410.04 & $<0.0001$ \\
A-pH & 5392.61 & 1 & 5392.61 & $17,919.86$ & $<0.0001$ \\
B-Initial metal ion concentration & 582.63 & 1 & 582.63 & 1936.09 & $<0.0001$ \\
C-Biosorbent dosage & 33.34 & 1 & 33.34 & 110.80 & $<0.0001$ \\
AB & 5.53 & 1 & 5.53 & 18.37 & 0.0016 \\
AC & 0.35 & 1 & 0.35 & 1.16 & 0.3071 \\
BC & 0.35 & 1 & 0.35 & 1.16 & 0.3071 \\
A $^{2}$ & 1544.41 & 1 & 1544.41 & 5132.14 & $<0.0001$ \\
B $^{2}$ & 1.82 & 1 & 1.82 & 6.04 & 0.0338 \\
C $^{2}$ & 9.70 & 1 & 9.70 & 32.24 & 0.0002 \\
Residual & 3.01 & 10 & 0.30 & & 0.6680 \\
Lack of fit & 1.20 & 5 & 0.24 & 0.66 & 0.3 \\
Pure error & 1.81 & 5 & 0.36 & & Not significant \\
Cor. total & 9238.63 & 19 & & & \\
\hline
\end{tabular}

biosorption of $\mathrm{Cu}(\mathrm{II})$. The probable $P$ values of each individual factors and their interactive terms suggest that $A, B$, $\mathrm{C}, \mathrm{AB}$ and $\mathrm{A}^{2}$ were significant model terms. Though the individual parameter effects namely $\mathrm{pH}$, initial concentration and biosorbent dosage were significant, combined effect of $\mathrm{pH}$ and initial concentration was more significant. Square effect of $\mathrm{pH}$ has also shown moderate significance on biosorption. Similar results were reported by Liu et al. (2018) for biosorption of copper using rape straw powder.
The mathematical equation of relationship between the response of system and independent input variables in terms of coded factors is:

$\%$ Removal $=+84.83+23.22 \times A-7.63 \times B+1.82 \times C$

$$
\begin{aligned}
& +0.83 \times A \times B-0.21 \times A \times C-0.21 \\
& \times B \times C-23.70 \times A^{2}-0.81 \times B^{2}-1.88 \times C^{2}
\end{aligned}
$$

From the above equation, it could be observed that factors $A$ and $C$ had a positive effect, i.e., proportional effect, 
while factor B had a negative effect, i.e., inverse effect on biosorption of copper.

\section{Optimization and substantiation of biosorption}

To estimate the maximum $\mathrm{Cu}$ (II) removal by spent $G$. acerosa and optimum processing conditions, optimization tool of RSM was used and predicted solution was shown in contour plot (Fig. 3). The maximum $\mathrm{Cu}(\mathrm{II})$ removal predicted is $96.362 \%$ at optimum process conditions of $\mathrm{pH}$ of 5.31, initial $\mathrm{Cu}$ (II) concentration of $23.87 \mathrm{mg} / \mathrm{l}$ and G. acerosa dosage of $0.41 \mathrm{mg} / \mathrm{l}$. The validity of optimization process was examined by conducting a fresh experiment at the above-predicted values and reported $94.25 \% \mathrm{Cu}$ (II) removal, which was in the vicinity of RSM predicted value. Hence, the predicted values of independent variables at maximum $\mathrm{Cu}$ (II) removal were considered as optimum process conditions for biosorption of $\mathrm{Cu}(\mathrm{II})$ onto spent $G$. acerosa.

\section{Analysis of interactive effects of two variables}

Response surface plots were used to investigate the interaction effects of any two variables on biosorption. Figure $4 \mathrm{a}$ shows the interactive effect of metal ions concentration and $\mathrm{pH}$ of the solution on biosorption of $\mathrm{Cu}(\mathrm{II})$. In contrast to a decrease in biosorption with an increase in concentration, a moderate increase was noticed with an increase in initial concentration, which clearly manifests the impact of $\mathrm{pH}$ over initial concentration on metal removal. Three-dimensional plot of effect of $\mathrm{pH}$ and biosorbent dosage on biosorption of $\mathrm{Cu}(\mathrm{II})$ is shown in Fig. 4b. It clearly shows the effect of $\mathrm{pH}$ over effect of biosorbent dosage. It could be observed

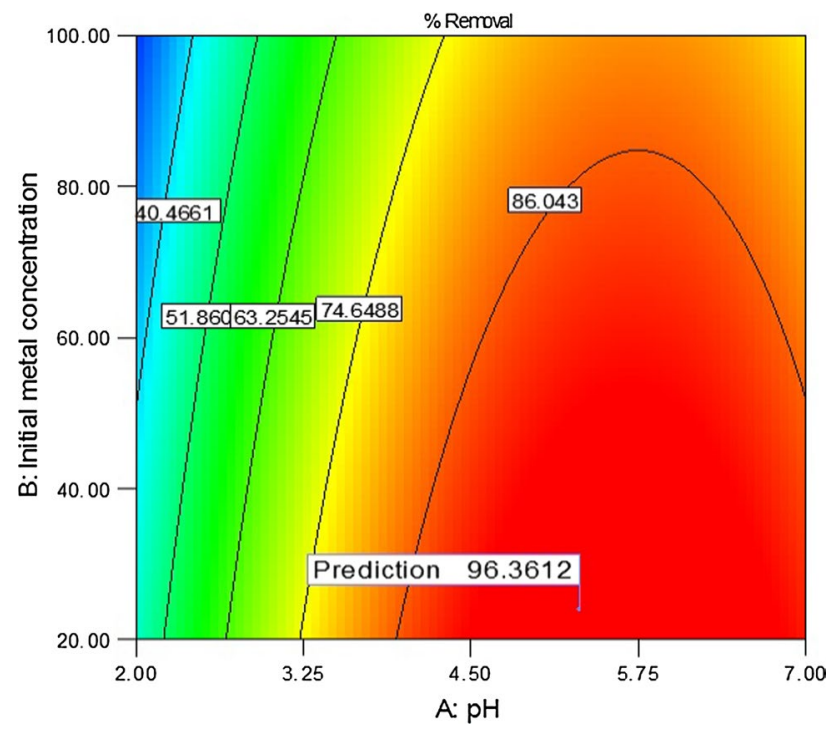

Fig. 3 Contour plot of optimum prediction of biosorption of $\mathrm{Cu}$ (II) onto spent $G$. acerosa by RSM that at higher biosorbent dosage, the $\%$ biosorption of $\mathrm{Cu}$ (II) was high, and a possible reason for this is that the increase in binding sites with dosage and the increase in negative charge on surface of biosorbent with $\mathrm{pH}$ together must have contributed for an increase in biosorption of $\mathrm{Cu}(\mathrm{II})$. The interactive effects of the biosorbent dosage and initial metal ions concentration can be inferred from the response plot (Fig. 4c), holding pH at central values. From Fig. 4c, it could be observed that there are no significant inferences. Since dosage and initial concentration have no significant effect on biosorption, the interaction effect of these two variables was also found to be insignificant. As shown in Table 3 of ANOVA, the $P$ value of the factor BC is very high, which also confirms the insignificance effect of that factor.

\section{Kinetic studies}

Kinetic modeling is fundamental in order to determine the affinity or capacity of the sorbent which in turn governs the residence time in the design of biosorption process. The fitness of kinetic data to pseudo-first- and second-order rate equations is described in Fig. 5, and corresponding rate constants, predicted copper uptake and $R^{2}$ values are reported in Table 4. Though the regression coefficient values of first-order model are in the range of $0.99-0.98$, the predicted metal uptakes are not in good agreement with the experimental values. Hence, pseudo-first-order rate equation is not appropriate for determining kinetics. In the case of pseudo-second order, high correlation coefficients and very closely predicted and experimental metal uptake values show the significance of the model for representing kinetics of biosorption of copper. Therefore, biosorption of copper onto spent G. acerosa follows pseudo-second-order model with chemisorption as a rate-limiting step. Further kinetic data were fitted to the Elovich model to investigate the biosorption mechanism, and the results are plotted in Fig. 5. The plots are linear with good correlation coefficients $\left(R^{2}\right.$ in the range of 0.985), indicating that the kinetic data follow the Elovich model. The intra-pore diffusion of copper ions is investigated by fitting the kinetic data to intra-particle diffusion model. Figure 6a shows that the kinetic data are not well correlated with the intra-particle diffusion model and also plots are not passing through origin. Hence, the same data are fitted to the Boyd model to find out exact rate-limiting step. $B_{t}$ values were calculated from the data and then plotted against contact time, as shown in Fig. 6b. It is clear that the plots are linear but not passing through the origin.

Good kinetic properties are very much essential for good adsorbents, i.e., they must be capable of transferring adsorbing molecules rapidly to adsorption sites. The kinetic parameters of this experiment are similar to the biosorption of kinetics of $\mathrm{Cu}$ (II) by other biosorbents derived from algal species like Halimeda gracilis (Jayakumar et al. 2015), 

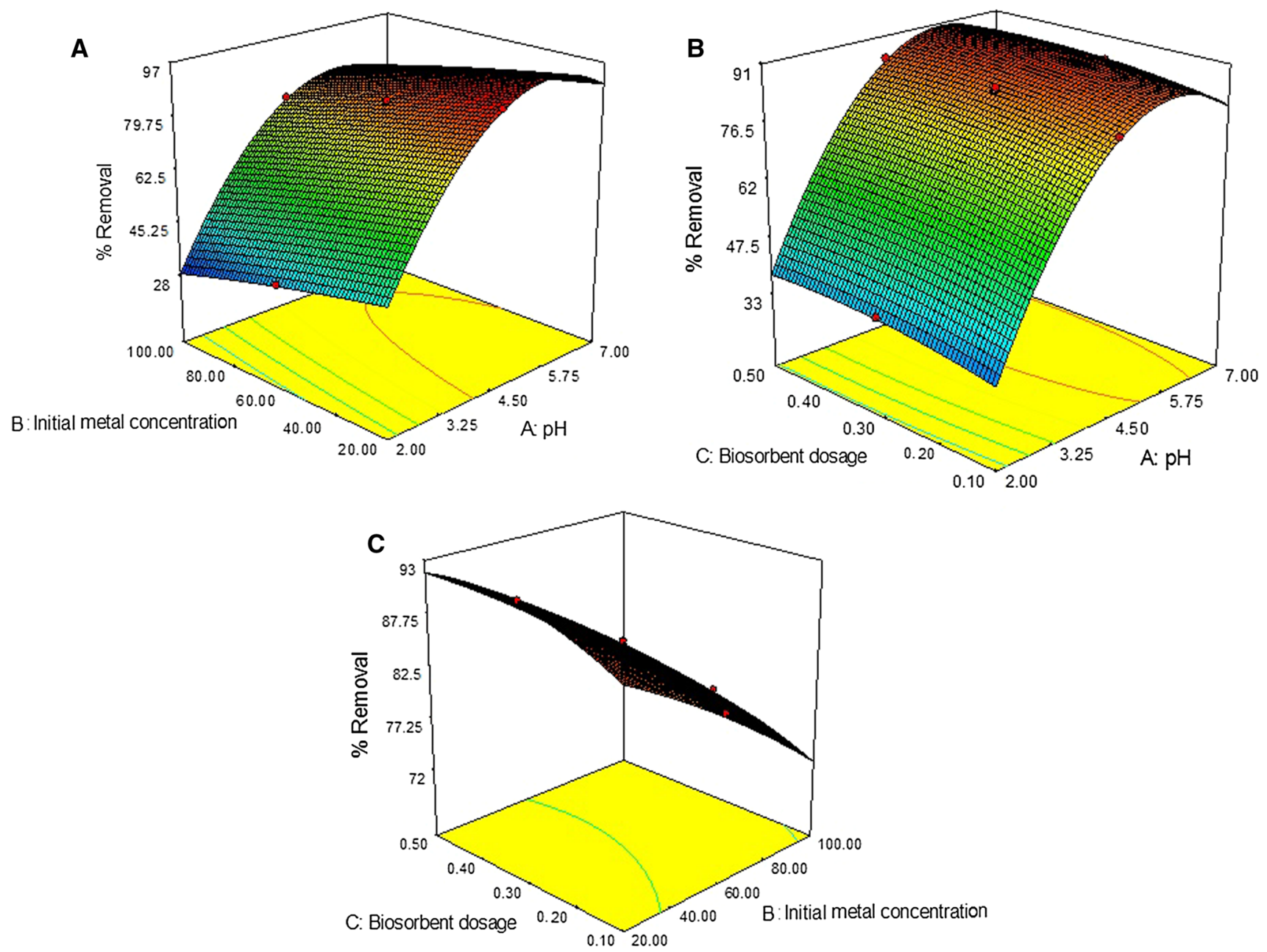

Fig. 4 Response surface plot for interactive effects of a initial concentration and $\mathrm{pH}, \mathbf{b}$ biosorbent dosage and $\mathrm{pH}$, $\mathbf{c}$ initial concentration and biosorbent dosage on biosorption of $\mathrm{Cu}(\mathrm{II})$ onto spent $\mathrm{G}$. acerosa

Euglena gracilis (Winters et al. 2017) and Arthrospira platensis (Markou et al. 2015). The fitness of data to secondorder model suggests that biosorption of $\mathrm{Cu}$ (II) onto the spent G. acerosa was controlled by chemisorptions and probably took place through surface exchange reactions until the surface active sites are fully occupied by metal ions. Moreover, fitness of data to the Elovich model reiterates the above-mentioned argument that the biosorption of copper follows chemisorptions. Fitness of kinetic data to intraparticle diffusion model (Fig. 6a) reveals that the linear plots are not passing through the origin which indicates that the biosorption of $\mathrm{Cu}(\mathrm{II})$ onto spent $G$. acerosa is controlled by external pore diffusion. Further investigation by fitting the data to Boyd model (Fig. 6b) with high correlation coefficient $\left(R^{2}=0.998\right)$ confirms that the film resistance is the rate-controlling step. Many researchers reported the similar results on biosorption of $\mathrm{Cu}$ (II) using other adsorbents (Kumar and Chawla 2014; Ofomaja et al. 2010; Yahaya et al. 2009).

\section{Conclusions}

In conclusion, the results of the present investigation indicate that biosorbent prepared from spent marine macro-algae G. acerosa, after extraction of agar, seems an efficient, most economic and eco-friendly adsorbent for biosorption of $\mathrm{Cu}(\mathrm{II})$ present in industrial wastewater. FTIR and SEM analysis established the presence of various functional groups on biosorbent surface and biosorption of $\mathrm{Cu}$ (II) ions onto G. acerosa. FCCCD of RSM was used to optimize the process conditions and maximize the $\mathrm{Cu}$ (II) removal. ANOVA showed a correlation coefficient $\left(R^{2}=0.99\right)$ significant $P$ value, thus ensuring significant adjustment of quadratic model with experimental values. Biosorption kinetics followed pseudo-second-order model with film resistance as rate-controlling mechanism. The findings of the present investigation indicated that spent $G$. acerosa can be successfully used for biosorption of $\mathrm{Cu}$ (II) from aqueous and industrial wastewater. 
Fig. 5 Biosorption of $\mathrm{Cu}(\mathrm{II})$ kinetics onto spent G. acerosa, a pseudo-first-order, b pseudosecond-order, c Elovich's models

Table 4 Pseudo-first- and second-order kinetic constants for biosorption of $\mathrm{Cu}$ (II) onto spent G. acerosa
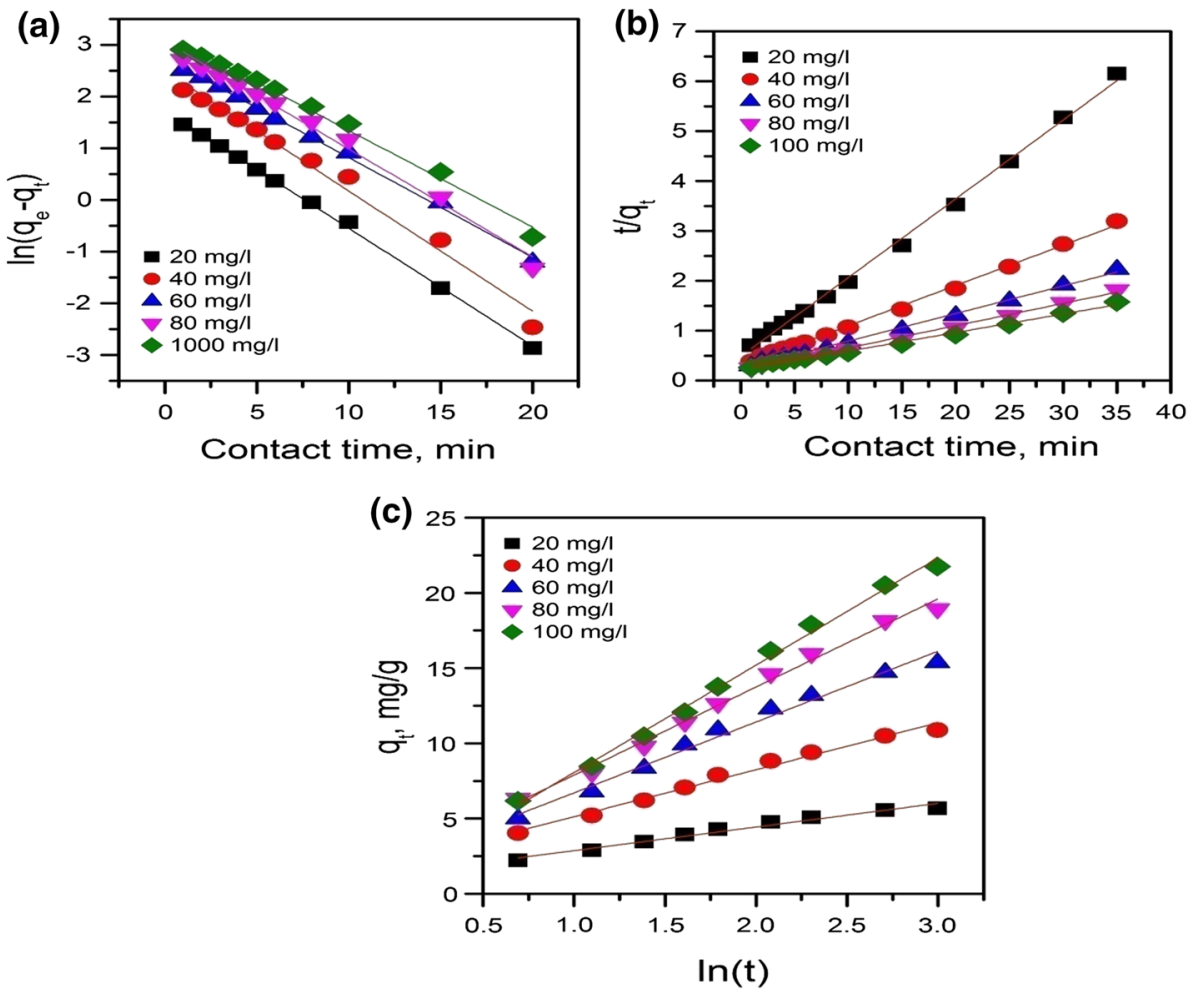

\begin{tabular}{|c|c|c|c|c|c|c|}
\hline \multirow{2}{*}{$\begin{array}{l}\text { Initial con- } \\
\text { centration } \\
(\mathrm{mg} / \mathrm{l})\end{array}$} & \multicolumn{3}{|c|}{ Pseudo-first order } & \multicolumn{3}{|c|}{ Pseudo-second order } \\
\hline & $\begin{array}{l}\text { Rate } \\
\text { constant } \\
{\left[k_{\mathrm{I}}(1 / \mathrm{min})\right]}\end{array}$ & $\begin{array}{l}\mathrm{Cu}(\mathrm{II}) \\
\text { uptake } \\
{\left[q_{\mathrm{eq}}(\mathrm{mg} / \mathrm{g})\right]}\end{array}$ & $\begin{array}{l}\text { Correlation } \\
\text { coefficient } \\
\left(R_{1}^{2}\right)\end{array}$ & $\begin{array}{l}\text { Rate } \\
\text { constant } \\
{\left[k_{\text {II }}(\mathrm{g} / \mathrm{min})\right]}\end{array}$ & $\begin{array}{l}\mathrm{Cu}(\mathrm{II}) \\
\text { uptake } \\
{\left[q_{\mathrm{eq}}(\mathrm{mg} / \mathrm{g})\right]}\end{array}$ & $\begin{array}{l}\text { Correlation } \\
\text { coefficient } \\
\left(R_{2}^{2}\right)\end{array}$ \\
\hline 20 & 0.227 & 3.321 & 0.998 & 0.0520 & 06.329 & 0.997 \\
\hline 40 & 0.232 & 5.652 & 0.985 & 0.0221 & 12.50 & 0.997 \\
\hline 60 & 0.192 & 6.727 & 0.997 & 0.0128 & 18.181 & 0.996 \\
\hline 80 & 0.208 & 8.415 & 0.987 & 0.0094 & 22.727 & 0.996 \\
\hline 100 & 0.186 & 9.292 & 0.991 & 0.0063 & 27.027 & 0.995 \\
\hline
\end{tabular}
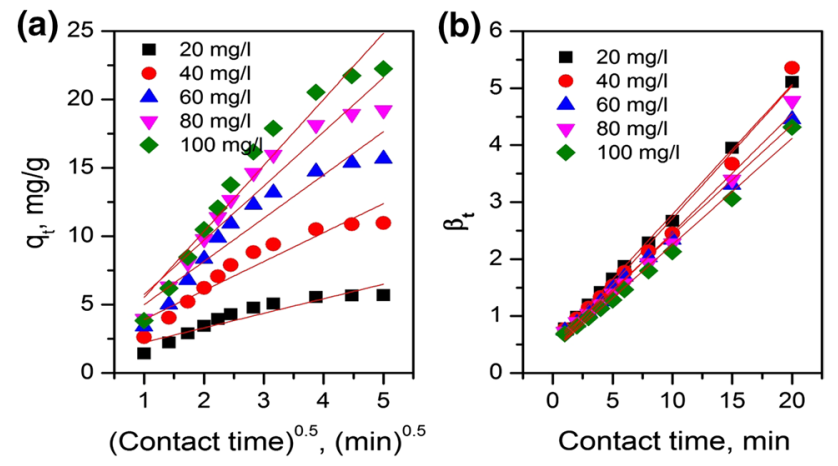

Acknowledgements We would like to thank the entire team of Center of Excellence for Advanced Materials, Manufacturing, Processing and Characterization (CoExAMMPC) of Vignan's Foundation for Science and Technology, Guntur, and Advanced Analytical Laboratory of Andhra University, Visakhapatnam, for their support in entire instrumental analysis.

Funding No external funding for this research.

\section{Compliance with ethical standards}

Conflict of interest The authors declare that they have no conflict of interest in the publication.

Fig. 6 Biosorption of $\mathrm{Cu}(\mathrm{II})$ kinetics onto spent G. acerosa, a intraparticle diffusion and $\mathbf{b}$ Boyd model 
Open Access This article is licensed under a Creative Commons Attribution 4.0 International License, which permits use, sharing, adaptation, distribution and reproduction in any medium or format, as long as you give appropriate credit to the original author(s) and the source, provide a link to the Creative Commons licence, and indicate if changes were made. The images or other third party material in this article are included in the article's Creative Commons licence, unless indicated otherwise in a credit line to the material. If material is not included in the article's Creative Commons licence and your intended use is not permitted by statutory regulation or exceeds the permitted use, you will need to obtain permission directly from the copyright holder. To view a copy of this licence, visit http://creativecommons.org/licenses/by/4.0/.

\section{References}

Abdolali A, Ngo HH, Guo W, Zhou JL, Zhang J, Liang S, Chang SW, Nguyen DD, Liu Y (2017) Application of a breakthrough biosorbent for removing heavy metals from synthetic and real wastewaters in a lab-scale continuous fixed-bed column. Bioresour Technol 229:78-87

Anantha RK, Kota S (2016) An evaluation of the major factors influencing the removal of copper ions using the egg shell (Dromaius novaehollandiae): Chitosan (Agaricus bisporus) composite. 3 Biotech 6(1):83

Anastopoulos I, Kyzas GZ (2015) Composts as biosorbents for decontamination of various pollutants: a review. Water Air Soil Pollut 226(3):1-16

Awual MR (2015) A novel facial composite adsorbent for enhanced copper(II) detection and removal from wastewater. Chem Eng J 266:368-375

Babu DJ, King P, Kumar YP (2018) Optimization of Cu(II) biosorption onto sea urchin test using response surface methodology and artificial neural networks. Int J Environ Sci Technol (Tehran). https://doi.org/10.1007/s13762-018-1747-2

Benaissa H, Elouchdi MA (2007) Removal of copper ions from aqueous solutions by dried sunflower leaves. Chem Eng Process 46(7):614-622

Boyd GE, Adamson AW, Myers LS Jr (1947) The exchange adsorption of ions from aqueous solutions by organic zeolites. II. Kinetics ${ }^{1}$. J Am Chem Soc 69(11):2836-2848

Calero M, Iáñez-Rodríguez I, Pérez A, Martín-Lara MA, Blázquez G (2018) Neural fuzzy modelization of copper removal from water by biosorption in fixed-bed columns using olive stone and pinion shell. Bioresour Technol 252:100-109

Chatterjee S, Kumar A, Basu S, Datta S (2012) Application of response surface methodology for methylene blue dye removal from aqueous solution using low cost adsorbent. Chem Eng J 181-182:289-299

Dulla JB, Sumalatha B, King P, Yekula PK (2018) Investigation on biosorption of Cd(II) onto Gelidiella acerosa (brown algae): optimization (using RSM and ANN) and mechanistic studies. Desalin Water Treat 107:195-206

Dursun AY (2006) A comparative study on determination of equilibrium, kinetic and thermodynamic parameters of biosorption of copper(II) and lead(II)ions onto pretreated Aspergillus niger. Biochem Eng J 28:187-195

Ekere NR, Agwogie AB, Ihedioha JN (2016) Studies of biosorption of $\mathrm{pb}^{2+}, \mathrm{Cd}^{2+}$ and $\mathrm{Cu}^{2+}$ from aqueous solutions using Adansonia digitata root powders. Int J Phytoremediat 18(2):116-125

Fu F, Wang Q (2011) Removal of heavy metal ions from wastewaters: a review. J Environ Manag 92(3):407-418
Guang JZ, Fu QP, Li JZ (2012) Biosorption of zinc and copper from aqueous solutions by two freshwater green microalgae Chlorella pyrenoidosa and Scenedesmus obliquus. Environ Sci Pollut Res 19:2918-2929

Izquierdo M, Gabaldón C, Marzal P, Álvarez-Hornos FJ (2010) Modeling of copper fixed-bed biosorption from wastewater by Posidonia oceanica. Bioresour Technol 101:510-517

Jayakumar R, Rajasimman M, Karthikeyan C (2015) Optimization, equilibrium, kinetic, thermodynamic and desorption studies on the sorption of $\mathrm{Cu}(\mathrm{II})$ from an aqueous solution using marine green algae: Halimeda gracilis. Ecotoxicol Environ Saf 121:199-210

Jerold M, Sivasubramanian V (2016) Biosorption of malachite green from aqueous solution using brown marine macro algae Sargassum swartzii, Desal. Water Treat 57:25288-25300

Kannan S (2014) FT-IR and EDS analysis of the seaweeds Sargassum wightii (brown algae) and Gracilaria corticata (red algae). Int J Curr Microbiol Appl Sci 3:341-351

Kellner R, Mermet JM, Otto M, Valcárce M, Widmer HM (2004) Analytical chemistry: a modern approach to analytical science. Wiley, Weinheim, $\mathrm{p} 774$

Khan TA, Mukhlif AA, Khan EA, Sharma DK (2016) Isotherm and kinetics modeling of $\mathrm{Pb}(\mathrm{II})$ and $\mathrm{Cd}(\mathrm{II})$ adsorptive uptake from aqueous solution by chemically modified green algal biomass. Model Earth Syst Environ 2:1-13

Kiran B, Thanasekaran K (2011) Copper biosorption on Lyngbya putealis: application of response surface methodology (RSM). Int Biodeter Biodegr 65:840-845

Krupanidhi S, Sreekumar A, Sanjeevi CB (2008) Copper and biological health. Indian J Med Res 128(4):448

Kumar R, Chawla J (2014) Removal of cadmium ion from water/ wastewater by nano-metal oxides: a review. Water Qual Exposure Health 5(4):215-226

Kumar V, Fotedar R (2009) Agar extraction process for Gracilaria cliftonii (Withell, Millar, and Kraft, 1994). Carbohyd Polym 78:813-819

Lammers K, Arbuckle-Keil G, Dighton J (2009) FT-IR study of the changes in carbohydrate chemistry of three New Jersey pine barrens leaf litters during simulated control burning. Soil Biol Biochem 41:340-347

Liu X, Chen ZQ, Han B, Su CL, Han Q, Chen WZ (2018) Biosorption of copper ions from aqueous solution using rape straw powders: optimization, equilibrium and kinetic studies. Ecotoxicol Environ Saf 150:251-259

Markou G, Mitrogiannis D, Çelekli A, Bozkurt H, Georgakakis D, Chrysikopoulos CV (2015) Biosorption of $\mathrm{Cu}^{2+}$ and $\mathrm{Ni}^{2+}$ by Arthrospira platensis, with different biochemical compositions. Chem Eng J 259:806-813

Meseguer VF, Ortuño JF, Aguilar MI, Pinzón-Bedoya ML, Lloréns M, Sáez J, Pérez-Marín AB (2016) Biosorption of cadmium(II) from aqueous solutions by natural and modified non-living leaves of Posidonia oceanic. Environ Sci Pollut Res 23:24032-24046

Ofomaja AE, Naidoo EB, Modise SJ (2010) Biosorption of copper(II) and lead(II) onto potassium hydroxide treated pine cone powder. J Environ Manag 91(8):1674

Sadhu K, Mukherjee A, Shukla SK, Adhikari K, Datta S (2014) Adsorptive removal of phenol from coke-oven waste water using Gondwana shale, India: experiment, modeling and optimization. Desalin Water Treat 52(34-36):6492-6504

Sari A, Tuzen M (2008) Biosorption of total chromium from aqueous solution by red algae (Ceramium virgatum): equilibrium, kinetic and thermodynamic studies. J Hazard Mater 160:349-355

Thilagan J, Kumar A, Rajasekaran K, Raja C (2015) Continuous fixed bed column adsorption of copper(II) ions from aqueous solution by calcium carbonate. Int J Eng Res 4(12):413-416 
Villanueva RD, Sousa AMM, Gonçalves MP, Nilsson M, Hilliou L (2010) Production and properties of agar from the invasive marine alga, Gracilaria vermiculophylla (Gracilariales, Rhodophyta). J Appl Phycol 22:211-220

Weber WJ, Morris JC (1964) Equilibria and capacities for adsorption on carbon. J Sanit Eng Div 90(3):79-108

Winters C, Guéguen C, Noble A (2017) Equilibrium and kinetic studies of $\mathrm{Cu}(\mathrm{II})$ and $\mathrm{Ni}(\mathrm{II})$ sorption on living Euglena gracilis. J Appl Phycol 29:1391-1398

Wuana R, Okieimen F (2011) Heavy metals in contaminated soils: a review of sources, chemistry, risks and best available strategies for remediation. International Scholarly Research Network. ISRN Ecology, New York. https://doi.org/10.5402/2011/402647
Yahaya YA, Don MM, Bhatia S (2009) Biosorption of copper(II) onto immobilized cells of Pycnoporus sanguineus from aqueous solution: equilibrium and kinetic studies. J Hazard Mater 161(1):189-195

Publisher's Note Springer Nature remains neutral with regard to jurisdictional claims in published maps and institutional affiliations. 